\title{
Reticular Facilitation of Visually Evoked Responses by Optic Tract Stimulation before and after Enucleation
}

\author{
Yoshinisa Nakai and Edward F. Domino ${ }^{1}$ \\ Michigan Neuropsychopharmacology Research Program, Department of \\ Pharmacology, Uniz'ersity of Michigan, Ann Arbor, Michigan 48104
}

\section{Received August 1, 1968}

\begin{abstract}
Reticular facilitation of evoked responses in the lateral geniculate nucleus and visual cortex elicited by ipsilateral optic tract stimulation was studied in cats prepared under diethyl ether-oxygen anesthesia, subsequently locally anesthetized, paralyzed with decamethonium, and placed on artificial respiration. In animals with an intact visual system, single electrical shocks to the reticular formation produced a more marked facilitation of the visually evoked response in primary visual cortex than in the lateral geniculate body. After bilateral enucleation of the eyeballs, the input-output relationship in both lateral geniculate and visual cortex dramatically shifted to the left, suggesting removal of tonic retinal inhibition. Although reticular stimulation still produced a slight facilitation at the neocortex and possibly at the lateral geniculate, it was much less than in intact preparations. The data suggest that reticular disinhibition of inhibitory discharge is still another phenomenon that must be considered in the over-all effects of reticular modulation of the visual system.
\end{abstract}

\section{Introduction}

Except for the retina, the visual system is relatively simple anatomically compared to other sensory systems. Evoked responses in the visual cortex and lateral geniculate nucleus to optic tract stimulation are well defined and are modulated by various portions of the brain $(2,14,21,27,33,37)$, especially by the reticular formation $(1,10-12,14-16,24,32,34)$. Since Chang's observation (13) that central evoked responses to optic nerve stimulation are enhanced by continuous illumination of the retina, the existence of a tonic inhibitory influence on the central visual pathway has been confirmed by many investigators. Removal of tonic retinal inhibition by ischemia of the retina $(3,9,26,31)$, ipsilateral or bilateral optic section, or enucleation of the eyeballs $(18,19)$ dramatically enhances evoked responses in the lateral geniculate and visual cortex. The role of the retina in reticular facilitation of evoked potentials in the central visual pathway

1 Supported in part by USPHS Grant MH-11846. Dr. Nakai's present address is Department of Pharmacology, Faculty of Medicine, Kyoto University, Kyoto, Japan. 
has not been adequately studied. The present article reports an attempt to analyze the interaction between retinal influences on reticular facilitation of evoked responses in the lateral geniculate body and visual cortex to ipsilateral optic tract stimulation.

\section{Methods}

Experiments were performed in 15 adult cats weighing $2.5-4.0 \mathrm{~kg}$. All surgery was under diethyl ether anesthesia. After fixation of the animal in a stereotaxic instrument, the skull over the left marginal gyrus was removed. Small holes were made in the remaining calvarium for insertion of bipolar stimulating or recording electrodes in the ipsilateral reticular formation, optic tract, and lateral geniculate nucleus. Location of electrode tips was determined with the aid of the stereotaxic brain atlas of Snider and Niemer (29). After all operative procedures were completed, the animals were locally anesthetized at all wound edges and immobilized with decamethonium (1-3 $\mathrm{mg} / \mathrm{kg} / \mathrm{hr}$, iv). Respiration was maintained with an artificial respirator and body temperature $\left(36-37^{\circ} \mathrm{C}\right)$ by means of an automatic heating pad. Evoked responses in the ipsilateral visual cortex were recorded with a monopolar silver ball tipped electrode using the nasion as an indifferent site. Potentials from the visual cortex and lateral geniculate body to optic tract stimulation were recorded simultaneously with two Grass P5 amplifiers and displayed on a Tektronix dualbeam oscilloscope. Single electrical pulses $(0.05 \mathrm{msec}$ and $15 \mathrm{v}$, usually three times threshold) were applied to the left optic tract (A11.0, L.7.0, $\mathrm{H}-4.0$ ). Single square wave pulses to the mesencephalic reticular formation were applied $50 \mathrm{msec}$ prior to optic tract stimulation with an intensity eight times that above the EEG activating threshold, the intensity to be most effective in facilitating vistal potentials (23). After reticular facilitation of the visually evoked responses of intact animals, bilateral enucleation of the eyeballs was performed under local anesthesia and the experiment subsequently repeated.

Monitoring of electrical brain activity was made with a Model III Grass EEG. Phonograph-needle electrodes were placed in the calvarium over the anterior sigmoid gyrus bilaterally, and a bipolar concentric needle electrode in the right hippocampus. Evoked potentials were recorded on Kodak Plus X photographic film using a Grass camera. Potentials were photographed every $5 \mathrm{sec}$. A timer triggered the camera, the two-channel Grass Model S8 stimulator, and the oscilloscope simultaneously. Peak-topeak amplitudes of each component were measured and mean amplitude calculated for groups of ten responses. At the end of an experiment, a $30 \sec 6 \mathrm{v}$ direct current was applied to each electrode for iron deposition 
and the brain perfused with potassium ferrocyanide and formalin solution for subsequent histological examination. Statistical analyses (Student $t$ test and linear regressions) were made as per Snedecor (28).

\section{Results}

Typical Evoked Responses in the Visual Cortex and Lateral Geniculate Nucleus. As described by the Bishop's and their colleagues (4-8), evoked potentials in the visual cortex to single shocks to the ipsilateral optic tract consist of four positive $\left(\mathrm{P}_{1}, \mathrm{P}_{2}, \mathrm{P}_{3}\right.$, and $\left.\mathrm{P}_{4}\right)$ and one slow negative component $\left(\mathrm{N}_{4}\right)$ (Fig. 1). The second positive component $\left(\mathrm{P}_{2}\right)$ is ustally very small or even absent. The $P_{1}$ component is the optic radiation potential representing presynaptic events, while $\mathrm{P}_{4}$ and $\mathrm{N}_{4}$ postsynaptic events are due to activation of neocortical visual neurons. Evoked potentials in the lateral geniculate nucleus due to optic tract stimulation also have a pre- and postsynaptic component. These have been called the tract $(\mathrm{t})$ and radiation waves ( $r$ ) by Bishop and McLeod (8). Typical potentials are illustrated in Fig. 1.

Reticular Modulation of the Visually Evoked Response. As was demonstrated by Bremer and Stoupel (10-12) and Dumont and Dell $(15,16)$.

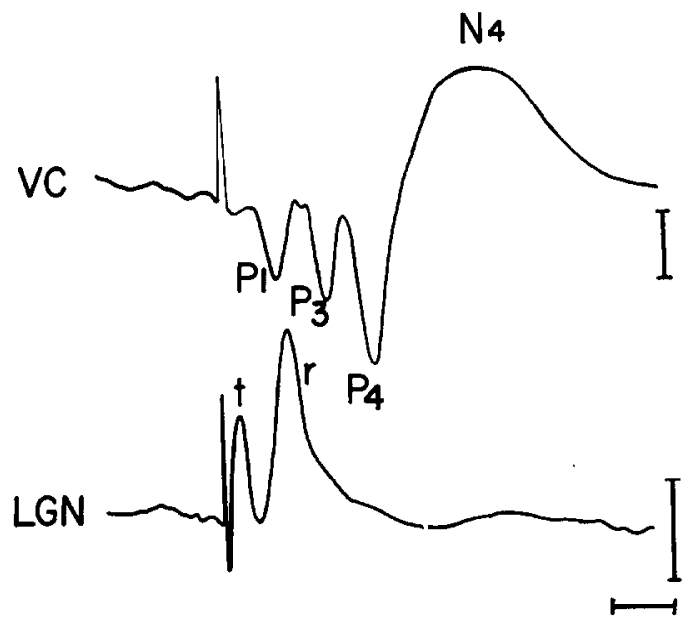

FIG. 1. Typical evoked potentials in the visual cortex and the lateral geniculate after optic tract stimulation. Responses to ipsilateral optic tract stimulation at three times threshold are illustrated. In the upper tracing, the visual cortex response (VC) consists of a series of positive wave forms of $\mathrm{P}_{1}, \mathrm{P}_{3}, \mathrm{P}_{4}$, and a slow negative component $\mathrm{N}_{4}$. The response in lateral geniculate (LGN) consists of the tract response $(t)$ and the radiation response $(r)$. The time course ( $2 \mathrm{msec}$ ) and microvolt calibration (upper, 200 ; lower, $500 \mu \mathrm{v}$ ) are shown. Negativity is represented in this tracing as upward. The lateral geniculate response was recorded with a concentric bipolar electrode. The visual cortical response was recorded monopolarly to the nasion. 
reticular stimulation of the optic tract produces a marked facilitation of cortical evoked responses. If one plots the time interval between single shocks to the reticular formation and optic tract on the $x$-axis and the height of the cortical and lateral geniculate evoked responses on the $y$-axis, the time course of these events can be better defined. In Fig. 2 is illustrated the time course of single reticular and optic tract stimuli on cortical and lateral geniculate evoked responses. The data were obtained from six cats. The upper graph shows the mean percentage change of control responses in the lateral geniculate nucleus of five cats. As can be seen, the mean tract responses $(\mathrm{t})$ were affected very little by reticular stimulation though they were sometimes slightly depressed in individual animals, a phenomenon that is consistent with evidence of a presynaptic inhibitory component (1, $22,25,32,34)$. In contrast, the radiation responses, as shown, were only slightly facilitated at an interval of $30-.50 \mathrm{msec}$. This slight facilitation of $10 \%$ was significant $(p<0.05)$. In marked contrast, the same reticular stimulation produced a dramatic enhancement of the postsynaptic component $\left(\mathrm{P}_{+}\right)$in the visual cortex at intervals greater than $20 \mathrm{msec}$. At a 50 msec interval, $\mathrm{P}_{4}$ showed a $260 \%$ increase in the cortical potential after reticular stimulation. At very short time intervals to $10 \mathrm{msec}$, an initial depressant effect on $\mathrm{P}_{4}$ was observed in two of five cats studied. A second peak facilitation of the $\mathrm{P}_{4}$ component at $150 \mathrm{msec}$ was also observed that gradually decreased with increasing time intervals. After $500 \mathrm{msec}$, responses were at prereticular stimulation levels. The cortical presynaptic component $\mathrm{P}_{1}$ was slightly facilitated within $30-50 \mathrm{msec}$ as would be consistent with the slight facilitation of the radiation response in the lateral geniculate nucleus. It has been previously observed $(30,35)$ that auditory evoked potentials are differentially affected depending upon the area of the reticular formation stimulated. Therefore, we studied the effects of stimulation of different regions of the reticular formation. Medullary $(\mathrm{P}-8, \mathrm{~L}, 3$, $\mathrm{H}-6$ ), midpontine (P-2, L $3 \mathrm{H}-5$ ), and midbrain reticular (A2, L3, H-1) loci of the reticular formation were stimulated to determine if there were any differential effects on the visually evoked response. As can be seen in Table 1, stimulation of any of these regions of the reticular formation produced primarily facilitation of visual cortical responses to ipsilateral optic tract stimulation. In particular, stimulation of the midpontine reticular formation produced the greatest facilitation of the visually evoked response.

Effect of Bilateral Enucleation on Visually Eroked Responses. The effects of reticular modulation of lateral geniculate and cortical responses were recorded before and after eyeball enucleation. In Fig. 3, the data obtained on lateral geniculate responses are illustrated. The mean amplitude of the presynaptic (left graph) and postsynaptic (right graph) components of six cats after increasing levels of optic tract stimulation is shown. 

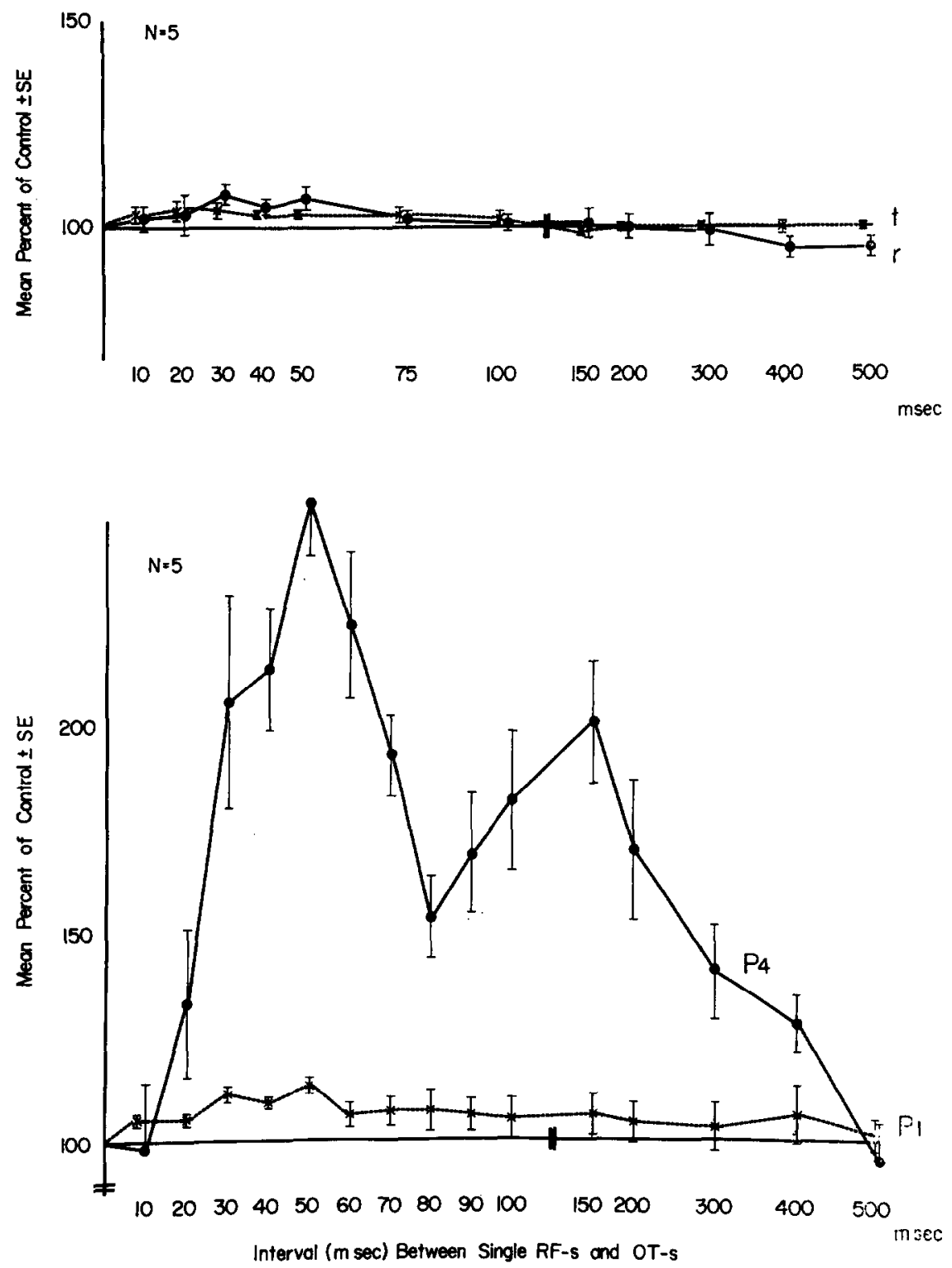

FIG. 2. Timc course of single-shock rcticular facilitation of evoked responses in lateral geniculate nucleus and visual cortex. The upper graph shows the mean percentage change of control responses in the lateral geniculate nucleus of five cats. Both the tract and radiation responses ( $t$ and $r$ ) are illustrated. Note that reticular stimulation ( $R F-s$ ) produced only a slight increase in the radiation response. In marked contrast, the same intensity of reticular stimulation produced a dramatic facilitation of the postsynaptic component $\left(\mathrm{P}_{4}\right)$ in the visual cortex (lower graph). The presynaptic component $P_{1}$ is only slightly facilitated. The parameters of reticular 
TABLE 1

Effect of Electrical Stimulation of Various Regions of the Reticulak Formation on the Cortical. Visuati.y Evoked Responsf.

\begin{tabular}{lccc}
\hline \multirow{2}{*}{ Region } & \multicolumn{3}{c}{ Mean percentage of control component $a$} \\
\cline { 2 - 4 } & $\mathrm{P}_{1}$ & $\mathrm{P}_{3}$ & $\mathbf{P}_{4}$ \\
\hline Medullary & $\%$ & $\%$ & $\%$ \\
Midpontine & $121.6 \pm 12.7$ & $152.2 \pm 15.0$ & $334.9 \pm 36.0$ \\
Midbrain & $122.9 \pm 12.2$ & $174.2 \pm 23.8$ & $407.9 \pm 21.2$ \\
\hline
\end{tabular}

a Plus or minus standard error, $\mathrm{N}=3(* \mathrm{~N}=6)$.

After enucleation, a very marked increased in amplitude of pre- and postsynaptic components of the lateral gcniculate response was observed. The threshold for optic tract stimulation of lateral geniculate responses decreased dramatically to one-half or one-third the previous intensity necessary for animals with an intact visual system. What was previously the threshold for minimal responses in the left lateral geniculate nucleus before enucleation now represented a very large potential. Therefore, systematic variation of optic tract stimuli was made before and after retinal enucleation. Reticular stimulation was maintained with single pulses eight times threshold intensity using a 50 -msec interval prior to single optic tract stimuli. As shown (Fig. 3), reduction of the presynaptic component of the lateral geniculate response was very slight. This reduction was still present after enucleation. In contrast, the postsynaptic radiation response was moderately facilitated by reticular formation stimulation before enucleation. However, after enucleation, facilitation of the postsynaptic component diminished.

With regard to the cortical visually evoked responses, the presynaptic component $\left(P_{1}\right)$ showed a decrease in the threshold intensity for optic tract stimulation after eyeball enucleation. However, its increase in amplitude was not as marked (see the left hand graph of Fig. 4). On the other hand, there was a dramatic increase in the amplitude of the postsynaptic component $\left(\mathrm{P}_{4}\right)$ of the visual cortical response after enucleation. In addition, the threshold intensity of optic tract stimulation was reduced to one-third to one-fourth that before enucleation. Reticular stimulation before enucleation produced only a slight facilitation of the $\mathrm{P}_{1}$ component that was similar to that after enucleation. However, these differences were not statistically sig-

stimulation were single square waves of $1-\mathrm{msec}$ square-wave pulses eight times threshold. Stimulation of the optic tract (OT-s) was with single square waves of 0.05 msec at three times threshold. 

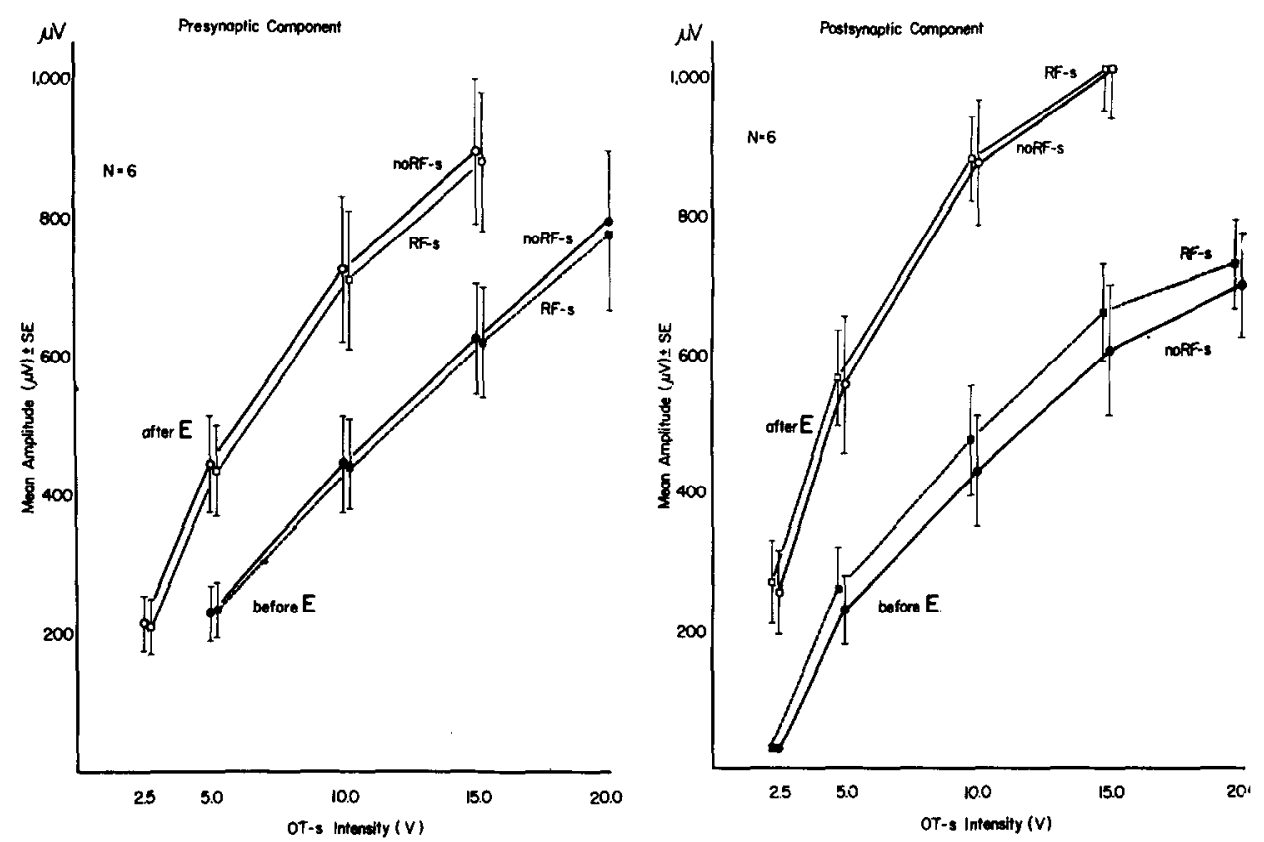

FiG. 3. Effect of reticular stimulation on evoked responses in the lateral geniculate nucleus before and after enucleation. The increasing intensity of optic tract stimulation is plotted on the $\mathrm{x}$-axis; the mean amplitude of the postsynaptic components on the $y$-axis. Intensity of reticular stimulation $50 \mathrm{msec}$ before with single pulses eight times threshold is shown. Note that before eyeball enucleation ( $E$ ), there is only a slight decrease of the mean presynaptic amplitude. After enucleation, the responses are essentially similar. In both instances, a very slight depression of presynaptic responses is present. In contrast, the postsynaptic component is moderately facilitated by reticular stimulation before eyeball enucleation. This effect persists although diminished after eyeball enucleation, suggesting a retinal component in the facilitation.

nificant. In marked contrast, reticular stimulation produced a dramatic facilitation of the postsynaptic component $\mathrm{P}_{4}$ before enucleation. After enucleation, reticular facilitation $\mathrm{P}_{4}$ diminished but was still present at low intensities of optic tract stimulation. With minimal voltages of $2.5-5.0 \mathrm{v}$, the mean amplitude of this response to reticular stimulation varied from 117 to $127 \%$ of control. In contrast, it was almost $250 \%$ elevated after enucleation.

An input-output analysis of synaptic transmission similar to that of others $(17,19)$ was performed in both the lateral geniculate nucleus and the visual cortex. Mean data are illustrated in Figs. 5 and 6 . As shown in Fig. 5, the amplitude of either the tract response (presynaptic component) in the lateral geniculate or the $\mathrm{P}_{1}$ response in visual cortex was plotted against the radiation response (postsynaptic component) in the lateral 

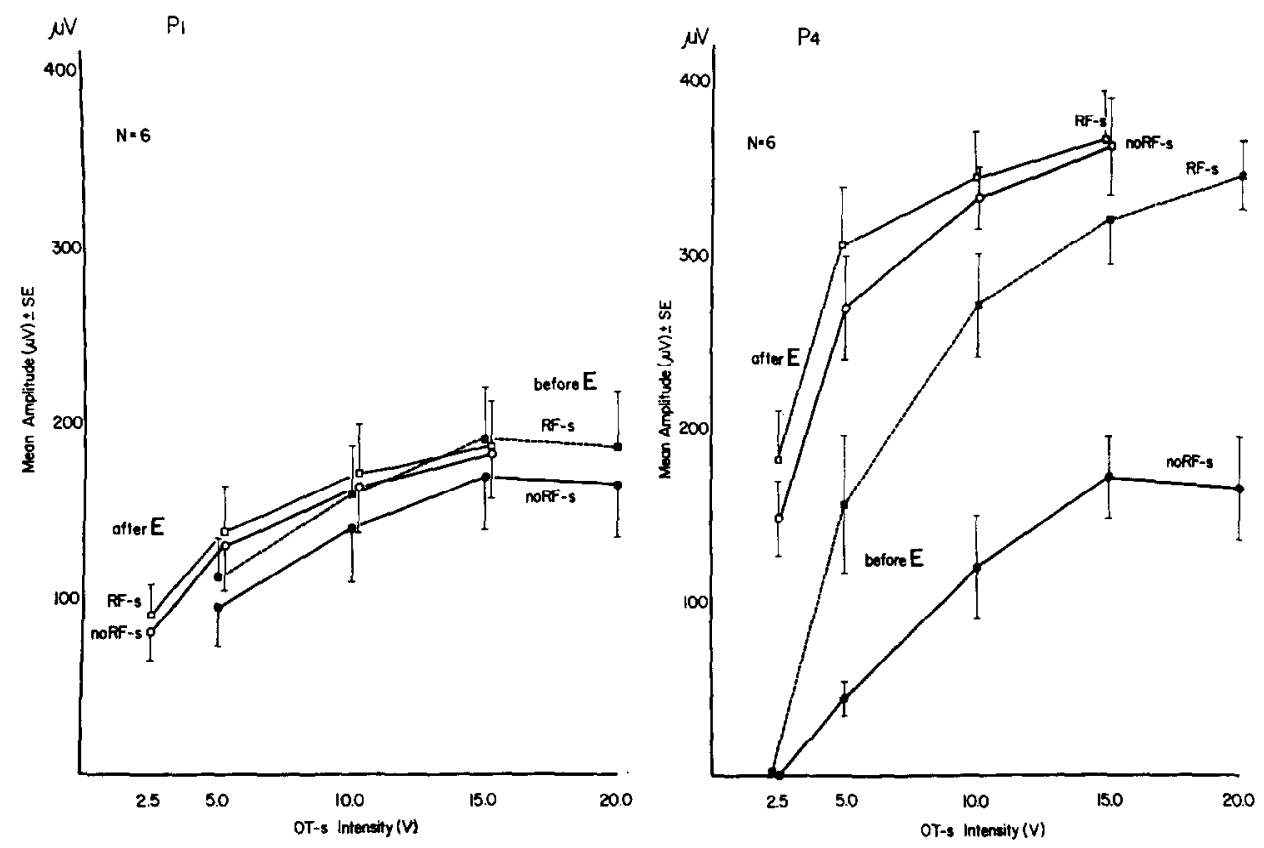

Fig. 4. Effect of reticular stimulation on evoked responses in the visual cortex before and after enucleation. The data are plotted similar to those in Fig. 3. The cortical presynaptic component $P_{1}$ is compared with the postsynaptic component $P_{4}$. Before eyehall enucleation, reticular stimulation causes a slight facilitation of $P_{1}$ that is present but reduced after eyeball enucleation. In marked contrast before eyeball enucleation, reticular formation stimulation causes a dramatic facilitation of the postsynaptic component $\mathrm{P}_{4}$. The facilitation is still present but diminished after eyeball enucleation. Note that after eyeball enucleation (E), the threshold for optic tract responses is dramatically reduced.

geniculate and the $\mathrm{P}_{4}$ response in the visual cortex before and after reticular stimulation. A linear regression analysis of the data was performed with the slopes as illustrated. A slight increase in amplitude of the postsynaptic component of the lateral geniculate response by reticular stimulation was observed with almost no change in amplitude of the presynaptic component; there was only a slight shift in the slope of the regression line (from 0.92 to 1.00 ) of lateral geniculate response. In contrast, a marked increase in the slope (from 0.95 to 1.62 ) of the regression line of the visual cortical responses was observed after reticular stimulation. These data show that reticular formation stimulation is more effective in facilitating the evoked responses in the visual cortex than in the lateral geniculate nucleus. The input-output relationship of evoked responses in the lateral geniculate nucleus and the visual cortex to optic tract stimulation was observed before and after bilateral eyeball enucleation (Fig. 6). A moderate shift of the 

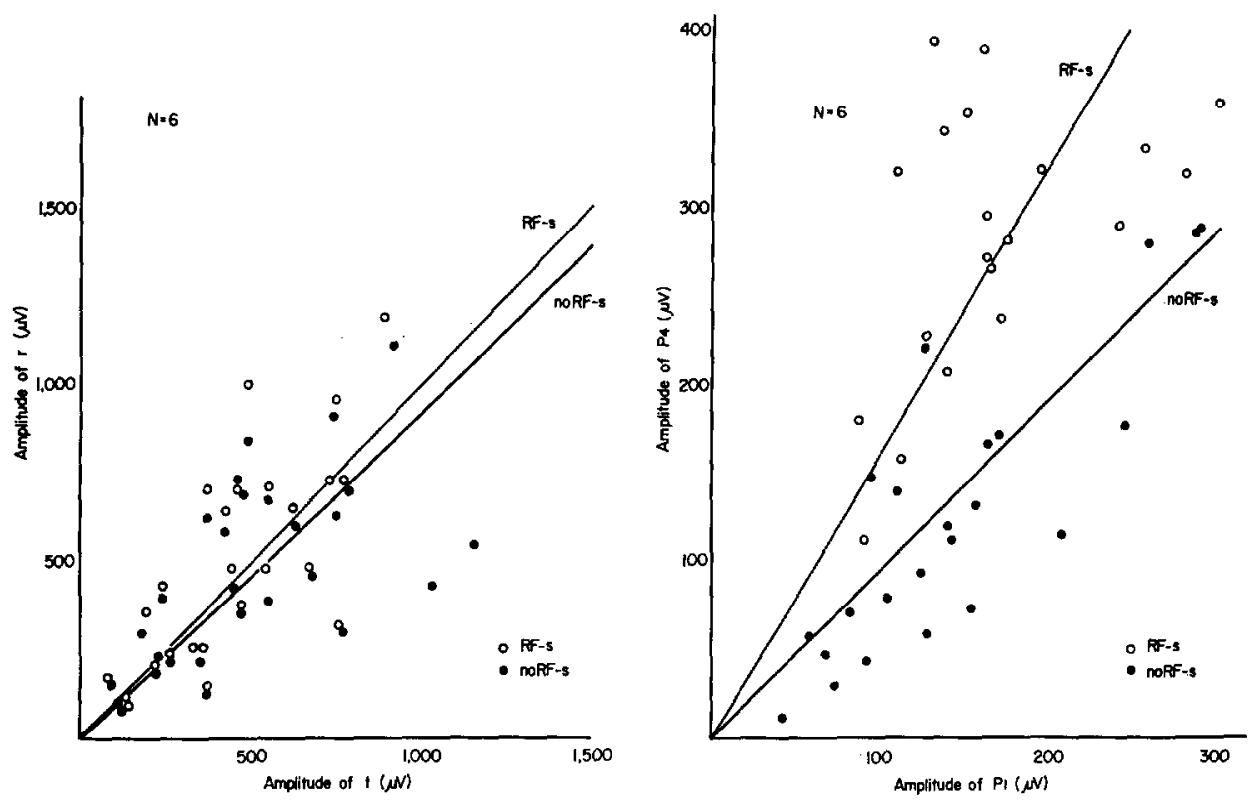

Fig. 5. Input-output relationship of evoked responses in lateral geniculate nucleus (left) and visual cortex (right) with and without reticular formation stimulation. The amplitude of either the presynaptic tract response $(t)$ in lateral geniculate nucleus or the $P_{1}$ response in visual cortex is plotted against the postsynaptic radiation response $(r)$ in lateral geniculate and the $P_{4}$ response in visual cortex. The solid circles represent before reticular stimulation and the open circles after reticular stimulation at eight times threshold intensity. The solid lines represent the linear regression before and the dotted lines after reticular stimulation. Note that $50 \mathrm{msec}$ after single-shock pulses to the reticular formation, there is only a slight shift in the slope of the regression line of the lateral geniculate in contrast with a marked increase in the slope of the regression line of visual cortex.

slope of the regression line (from 0.92 to 1.22 ) in the lateral geniculate nucleus was observed after enucleation; however, in the visual cortex, the shift of the regression line (from 0.96 to 2.04) was more obvious after enucleation.

\section{Discussion}

Both excitatory and inhibitory reticular influences to the lateral geniculate nuclei have been shown $(1,2,20,24)$. We observed a slight enhancement of the postsynaptic component of the lateral geniculate responses to optic tract stimulation by a single reticular shock prior to optic tract stimulation, as shown by Suzuki and Taira (34). Although no facilitation in the mean presynaptic component of lateral geniculate responses was observed, in some cases a slight depression in the presynaptic component by the reticular 

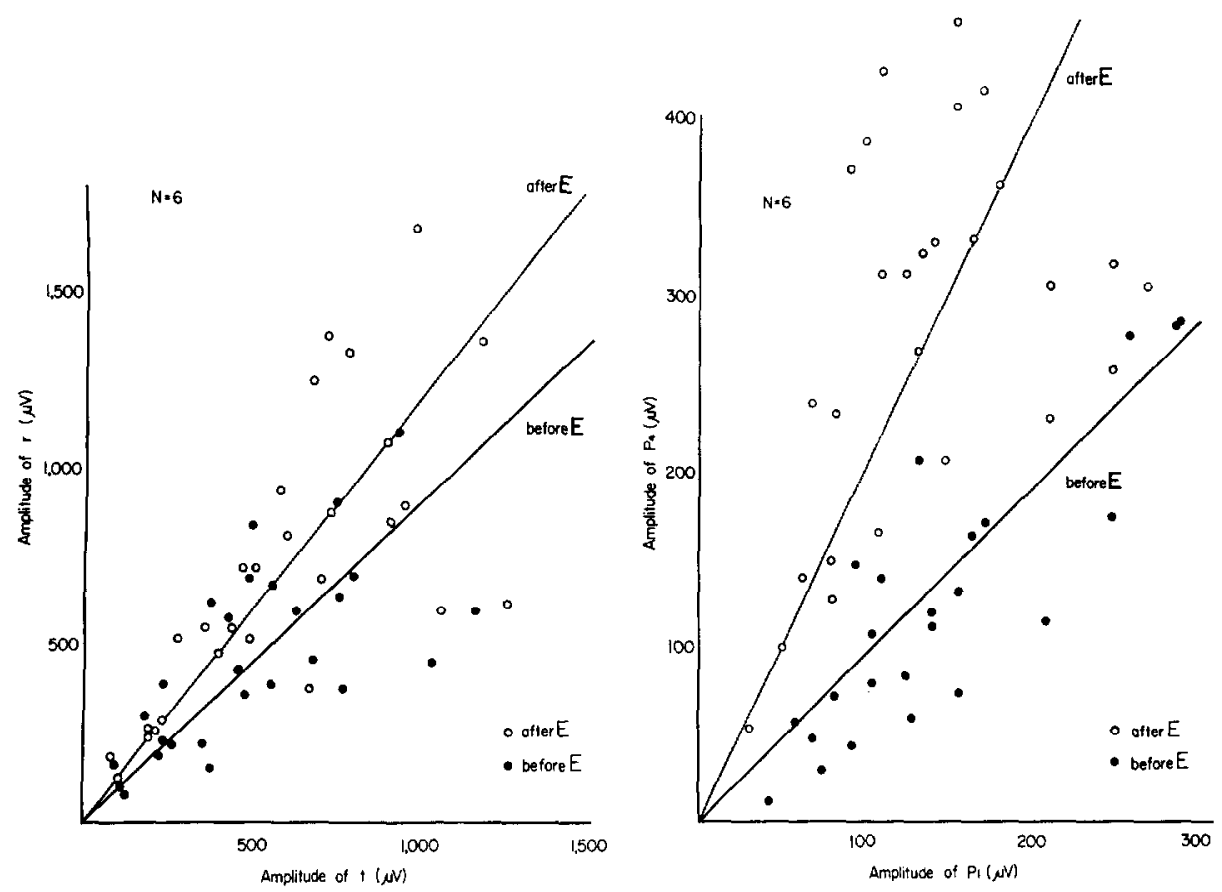

Fic. 6. Input-output relationships of evoked responses in lateral geniculate nucleus (left) and visual cortex (right) before and after enucleation. The amplitude of either the presynaptic tract response $(t)$ in lateral geniculate or the $P_{1}$ response in visual cortex is plotted against the postsynaptic radiation response $(r)$ in lateral geniculate and the $\mathrm{P}_{4}$ response in visual cortex as in Fig. 5. The solid circles represent before bilateral enucleation of eyeballs and the open circles after enucleation. The solid lines represent the linear regression before and the dotted lines after enucleation. Note the moderate shift of the slope of the regression lines of both the visual cortex and lateral geniculate after enucleation.

formation stimulation was observed. These findings are compatible with reports that presynaptic inhibition to lateral geniculate neurons can be caused by reticular formation stimulation $(1,22,25,32,34)$. On the other hand, we usually observed only facilitation of visual cortical responses by single reticular formation stimuli in both presynaptic and postsynaptic components as has previously been demonstrated $(10-12,15,16)$. In the time course of reticular facilitation of the postsynaptic cortical responses, a clouble peak was observed at 50 and 150 msec intervals; the cause for this is unknown.

It is known that tonic inhibitory effects from the retina act on the central visual pathway. After removal of this tonic retinal inhibition, through blockade of retinal activity by ischemia of the retina $(3,9,31)$, ipsilateral 
or bilateral optic nerve section, or enucleation of eyeballs $(18,19)$, the evoked responses in the visual cortex and the lateral geniculate nucleus are tremendously enhanced. It is reasonable to assume that facilitation of the evoked responses after deafferentation of the retina is caused by the removal of retinal tonic inhibitory discharge. Suzuki (31) suggested that this was postsynaptic inhibition from the retina on the lateral geniculate nucleus since he found no change in optic tract events. The facilitatory effect of reticular formation stimulation on visually evoked responses could be due in part to reticular inhibition of tonic retinal inhibition (disinhibition). However, there was still a very slight facilitation of the lateral geniculate response by reticular stimulation, and the facilitatory effect of reticular formation stimuli on the cortical visually evoked responses, though diminished, was still observable after bilateral eyeball enucleation. Therefore, it appears that the reticular formation directly facilitates these structures as well. There is other evidence that visually evoked responses are modulated by the cerebral cortex $(21,32,36)$ the hippocampus $(27)$, the hypothalmus (14) and other brain systems. Thus, the total phenomenon of reticular facilitation of the visually evoked response is indeed a most complex one. The present study indicates that peripheral retinal disinhibition is still another factor that must be considered.

\section{References}

1. Angel, A., F. Magni, and P. Strata. 1965. Excitability of intra-geniculate optic tract fibres after reticular stimulation in the midpontine pretrigeminal cat. Arch. Ital. Biol. 103 : 668-693.

2. Angel, A., F. Magni, and P. Strata. 1967. The excitability of optic terminals in the lateral geniculate nucleus after stimulation of visual cortex. Arch. Ital. Biol. 105 : 104-117.

3. Arduini, A., and T. Hirao. 1960. Enhancement of evoked responses in the visual system during reversible retinal inactivation. Arch. Ital. Biol. 98: 182-205.

4. Bishop, G. H., and M. H. Clare. 1952. Sites of origin of electric potentials in striate cortex. J. Neurophysiol. 15: 201-220.

5. Bishop, G. H., and J. O'Leary. 1938. Potential records from the optic cortex of the cat. J. Neurophysiol. $1: 391-404$.

6. Bishop, G. H., and J. S. O'LeARY. 1940. Electrical activity of the lateral geniculate of cats following optic nerve stimuli. J. Neurophysiol. 3 : 308-322.

7. Bishop, P. O. 1953. Synaptic transmission. An analysis of the electrical activity of the lateral geniculate nucleus in the cat after optic nerve stimulation. Proc. Roy. Soc. London Ser. B 141 : 362-392.

8. Bishop, P. O., and J. G. McLeon. 1954. Nature of potentials associated with synaptic transmission in lateral geniculate of cat. $J$. Neurophysiol. $17: 387-414$.

9. Bishop, P. O., W. R. Levick, and W. O. Williams. 1964. Statistical analysis of the dark discharge of lateral geniculate neurones. J. Hhysiol. London 170: 598-612.

10. Bremer, F. 1960. Analyse des processus corticaux de l' éveil. Electroencephalog. Clin. Neurophysiol. Suppl. 13: 125-136. 
11. Bremer, F., and N. Stoupez. 1959. Etude pharmacologique de la facilitation des réponces corticales dans l'éveil réticulaire. Arch. Intern. Pharmacodyn. 122: 234-248.

12. Bremer, F., and N. Stocplic. 1959. Facilitation et inhibition des potentiels évoqués corticaux dans l'éveil cérébral. Arch. Intcrn. Physiol. 67: 240-275.

13. Chang, H. T. 1952. Cortical response to stimulation of lateral geniculate body and the potentiation thereof by continuous illumination of retina. J. Neurophysiol. $15: 5-26$.

14. CHI, C. C., and J. P. FlynN. 1968. The effects of hypothalamic and reticular stimulation on evoked responses in the visual system of the cat. Electroencephalog. Clin. Neurophysiol. $24: 343-356$.

15. Dumont, S., and P. Dezl. 1958. Facilitations spécifiques et nonspécifiques des résponses visuelles corticales. J. Physiol. Paris $50: 261-264$.

16. Dumont, S., and P. Dell. 1960. Facilitation réticulaire des mécanismes visuels corticaux. Electroencephalog. Clin. Ncurophysiol. $12: 769-796$.

17. Ersman, J. A., S. M. Hansen, and W. Burke. 1967. Synaptic responsiveness in the lateral geniculate nucleus of the alert cat. Vision Rcs. 7: 385-399.

18. Erulkar, S. D., and M. Fillenz. 1958. Patterns of discharge of single units of the lateral geniculate body of the cat in response to binocular stimulation. J. Physiol. London $140: 6 \mathrm{P}-7 \mathrm{P}$.

19. Hansen, S. M., I. S. C. Brtce, and W. Burke. 1967. The effect of retinal illumination and retinal blockade on synaptic transmission in the lateral geniculate nucleus of the cat. Vision Res. $7: 401-414$.

20. Hubel, D. H. 1960. Single unit activity in lateral geniculate body and optic tract of unrestrained cats. J. Physiol. London $150: 91-104$.

21. Iwama, K., H. Sakakura, and T. Kasamatsu. 1965. Presynaptic inhibition in the lateral geniculate body induced by stimulation of the cerebral cortex. Japan. I. Physiol. 15: 310-322.

22. Kahn, N., F. Magni, and R. V. Pillai. 1967. Depolarization of optic fiber endings in the lateral geniculate body. Arch. Ital. Biol. 105: 573-582.

23. Nakai, Y., and E. F. Domino. 1968. Differential effects of pentobarital, ethyl alcohol and chlorpromazine in modifying reticular facilitation of cat visual evoked responses. Intern. J. Neuropharmacol. (Submitted for publication.)

24. Ogawa, T. 1963. Midbrain reticular influences upon single netrons in lateral geniculate nucleus. Science 139 : 343-344.

25. Pecci-Sanenra, J., P. D. Wilson, and R. W. Doty. 1965. Presynaptic inhibition in primate lateral geniculate nucleus. Nature $210: 740-742$.

26. Posternak, J. M., T. C. Fleming, and E. V. Evarts. 1959. Effect of interruption of the visual pathway on the response to geniculate stimulation. Science $129: 39-40$.

27. Redping, F. K. 1967. Modification of sensory cortical evoked potentials by hippocampal stimulation. Electroencephalog. Clin. Neurophysiol. 22 : 74-83.

28. Snedecor, G. W. 1956. "Statistical Methods Applied to Experiments in Agriculture and Biology," 5th ed., pp. 1-534. Iowa State College Press, Ames, Iowa.

29. Snider, R. S., and W. T. Niemer. 1961. "A Stereotaxic Atlas of the Cat Brain." Univ. of Chicago Press, Chicago, Illinois.

30. Steriade, M., and M. Demetrescu. 1962. Reticular facilitation of responses to acoustic stimuli. Electroencephalog. Clin. Neurophysiol. 14: 21-36.

31. SuzUKI, H. 1967. Effect of reversible retinal blockage on population response of the lateral geniculate nucleus. Japan. J. Physiol. 17 : 335-347. 
32. Suzuki, H., and M. Ichijo. 1967. Tonic inhibition in cat lateral geniculate nucleus maintained by retinal spontaneous discharge. Japant. J. Physiol. 17: $599-612$.

33. Suzuki, H., and E. Kato. 1965. Cortically induced presynaptic inhibition in cat's lateral geniculate body. Tohoku J. Exptl. Med. $86: 277-289$.

34. SuzUki, H., and N. TaIRa. 1961. Effect of reticular stimulation upon synaptic transmission in cat's lateral geniculate body. Japan. J. Physiol. 11: 641-655.

35. Takaori, S., Y. Nakai, M. Sasa, and K. Shimamoto. 1966. Central depressants and evoked click responses with special reference to the reticular formation in the cat. Japan. J. Pharmacol. 16 : 264-275.

36. VastolA, E. F. 1955. Steady potential responses in the lateral geniculate body. Electroencephalog. Clin. Neurophy'siol. $7: 557-567$.

37. Widén, L., and C. Ajmone Marsan. 1960. Effects of corticipetal and corticifugal impulses upon single elements of the dorsolateral geniculate nucleus. Exptl. Neurol. 2: 468-502. 